ISSN 1112-9867

http://www.jfas.info

\title{
INVESTIGATION OF UNDERGROUND RESISTIVITY MEASUREMENT AT KING SEJONG STATION, ANTARCTIC
}

\author{
K. N. Juhari ${ }^{1}$, F. A. M. Kasran ${ }^{1}$ and M. H. Jusoh ${ }^{1,2, *}$ \\ ${ }^{1}$ Faculty of Electrical Engineering, UniversitiTeknologi MARA, 40450 Shah Alam, Selangor, \\ Malaysia \\ ${ }^{2}$ Applied Electromagnetic Research Group, Advance Computing and Communication \\ Communities of Research, UniversitiTeknologi MARA, 40450 Shah Alam, Selangor,
} Malaysia

Published online: 17 October 2017

\begin{abstract}
The present work has been made to investigate underground resistivity variation at King Sejong Station, Antarctic by conducting a four-point resistivity method of Wennerarray. The 3-hour interval of underground resistivity data were collected and analysed in order to evaluate the underground resistivity variation at high-latitude region. From the analysis, it reveals that the underground resistivity is controlled by solar variation as it shows increasing pattern during day-time and decline as night-time approaches. Furthermore, we also analysed the space weather activities to observe any electromagnetic anomaly that could contribute to the underground resistivity variation. Plus, a comparison analysis of underground resistivity at high-latitude region and equatorial region is discussed in this paper. This research serves as a basis in understanding the characteristic of underground resistivity at polar region.
\end{abstract}

Keywords: resistivity method; Wenner; Antarctic; soil; solar variation.

Author Correspondence, e-mail: huzaimy_uitm@yahoo.com

doi: http://dx.doi.org/10.4314/jfas.v9i5s.35 


\section{INTRODUCTION}

A geo-electrical resistivity measurement is one of the established geophysical methods in exploring and analyzing the subsurface profile. There are other various methods which are commonly used in geophysical exploration such as electromagnetic induction, gravity, seismic and ground penetrating radar in which these methods vary depending on the purpose of the measurement. Generally, the geophysical methods are implement to conduct various geological, environmental and engineering surveys such as mineral exploration, void detection and geotechnical investigations [1].

There are also standards which have been established that serve as a guideline in conducting underground resistivity measurement such as IEEE Guide for Measuring Earth Resistivity, Ground Impedance and Earth Surface Potential of A Grounding System (IEEE Std. 81-2012) [2] and British Standard Code of Practice for Protective Earthing of Electrical Installations (BS 7430:2011) [3]. These guidelines provide a detailed explanation regarding a standard procedure and methods to perform the resistivity measurement. In practical, these standards are commonly referred in designing an earthing system by which resistivity measurement is crucial to be conducted in order to evaluate the ground impedance.

In geology, there are several factors which contribute to the changes in the underground resistivity including nature of the soils, voids arrangement, moisture content, solute concentration and temperature [4]. Different types of soils have different complexion which depends on the particle size distribution and thus they exhibit different electrical resistivity values. For example, sands normally have higher resistivity than silt and clay due to its granular size of particles distribution [5]. The arrangement of voids (empty spaces between the rocks or cavities of the rocks) often been linked to the porosity which is the percentage of air and water with respect to the water potential.

Other than that, soil resistivity can also be influenced by the soil moisture content. The presence of water can greatly facilitate the conduction of electrical current in the pores and increase the electrical conductivity. Therefore, it directly decreases the soil's electrical resistivity. Furthermore, solute concentration also affects the conduction of electrical current as different ionic compositions have different mobility. Hence, electrical conductivity varies depending on the solute concentration. Besides that, it has also been suggested that the 
increasing in temperature causes the ion to agitate aggressively and decrease the viscosity of the fluid. Thus, the electrical resistivity decreases with the increase in temperature.

Based on the above explanation, soil resistivity can vary extensively in many ways and too many extents upon changing in these factors. Table 1 and Table 2 show the typical resistivity values for different soil conditions [6].

Table 1. Typical resistivity values for different type of soil

\begin{tabular}{ccc}
\hline Type of Soil & Typical Resistivity Values $(\mathbf{\Omega m})$ & Usual Limit $(\mathbf{\Omega m})$ \\
\hline Sea water & 2 & 0.1 to 10 \\
\hline Clay & 40 & 8 to 70 \\
\hline Ground well and spring water & 50 & 10 to 150 \\
\hline Clay and sand mixtures & 100 & 4 to 300 \\
\hline Shale, slates and sandstone & 120 & 10 to 100 \\
\hline Peat, loam and mud & 150 & $5-250$ \\
\hline Lake and brook water & 250 & $100-400$ \\
\hline Sand & 2000 & $200-3000$ \\
\hline Moraine gravel & 3000 & $40-10000$ \\
\hline Ridge gravel & 15000 & $3000-30000$ \\
\hline Solid granite & 25000 & $10000-50000$ \\
\hline Ice & 100000 & $10000-100000$ \\
\hline
\end{tabular}

Table 2. Variation of soil resistivity with soil temperature

\begin{tabular}{cc}
\hline Soil Temperature $\left({ }^{\mathbf{0}} \mathbf{C}\right)$ & Typical Resistivity Values $(\mathbf{\Omega m})$ \\
\hline $\mathbf{2 0}$ & 72 \\
\hline $\mathbf{1 0}$ & 99 \\
\hline $\mathbf{0}$ (water) & 138 \\
\hline $\mathbf{0}$ (ice) & 300 \\
\hline $\mathbf{- 5}$ & 790 \\
\hline $\mathbf{- 1 5}$ & 3300 \\
\hline
\end{tabular}

Interestingly, some researches also have revealed that the changes in underground resistivity 
could be attributed by the external parameters originated outside of the lithosphere. Fundamentally, it has been proposed that the variability in the ionospheric current which is induced by the solar activity generates the formation of underground induced current (telluric current) in the lithosphere by some kind of electromagnetic induction mechanism [7-8]. Hence, the lithosphere would be much more electrically conductive resulted by the flow of the induced current [9]. Theoretically, the electrical resistivity would change too as it is inversely proportional to the electrical conductivity.

\subsection{Antarctic Soils}

Antarctic is the fifth largest continent in the world which is located at the southern hemisphere of the Earth's polar region. The land is mainly covered by the ice by which less than $0.4 \%$ of the continent is an ice-free area. Antarctic experiences harsh weather conditions and thus known as the coldest, windiest and driest continent in the world. Near the coast, its annual temperature averaging about $-10^{\circ} \mathrm{C}$ whereby in the inland, its annual mean temperature is around $-60^{\circ} \mathrm{C}[10]$. The extreme environment of Antarctic exemplify its soil conditions which are characterized by very low soil temperature and low moisture content. The average annual soil temperature ranging in between $-15^{\circ} \mathrm{C}$ and $-40^{\circ} \mathrm{C}$.

Antarctic soils are made up of surface pavement and an active layer. The surface pavement layer comprises of variety types of soil such as gravel, stones or boulders. Meanwhile, the active layer lies underneath the surface pavement is loosely arranged when not frozen and ice-cemented. Typically, the depth of active layer varies from $17 \mathrm{~cm}$ to $55 \mathrm{~cm}$ [11].

\subsection{Theory and Basic Principles of Resistivity Method}

Soil resistivity is often described as the ability of the soil to resist the flow of current. Theoretically, basic principle of resistivity is driven from the Ohm's law where it explains the relationship between electrical current, potential and resistance. For a simple analogous explanation, consider a cylinder with $\mathrm{L}$ as a length of the cylinder $(\mathrm{m})$ and $\mathrm{A}$ is a cross-sectional area of a cylinder $\left(\mathrm{m}^{2}\right)$. Thus, the resistivity of the body is stated as below

$\rho=R\left(\frac{A}{L}\right)$

where $\mathrm{R}$ is electrical resistance $(\Omega)$. The electrical resistance $(\mathrm{R})$ is defined based on the Ohm's Law as follows 
$\mathrm{R}=\frac{\mathrm{V}}{\mathrm{I}}$

with $\mathrm{V}$ being the potential (V) and I is the electrical current (A).

In a homogenous soil, the electrical equipotentials are perpendicular to the electric field lines that radiate away from the point source as described in Fig. 1 [12]. Thus, the current density, J $\left(\mathrm{A} / \mathrm{m}^{2}\right)$ is calculated as below

$\mathrm{J}=\frac{\mathrm{I}}{2 \pi \mathrm{r}^{2}}$

where I is electrical current (A) and $2 \pi r^{2}$ is the surface area of a hemispherical with radius, $r$. Hence, the potential, $\mathrm{V}$ can be expressed as in the form below

$$
\mathrm{V}=\frac{\rho \mathrm{I}}{2 \pi \mathrm{r}}
$$

Basically, the underground resistivity measurement is conducted by injecting four probes of electrodes into the ground at the arbitrary point in which the two outer electrodes $\left(\mathrm{C}_{1}\right.$ and $\left.\mathrm{C}_{2}\right)$ represent current electrode whereby the two inner electrodes $\left(\mathrm{P}_{1}\right.$ and $\left.\mathrm{P}_{2}\right)$ act as potential electrode. The underground resistivity is obtained by supplying current via the current electrodes and the potential difference is measured between the two inner electrodes where the ground itself acts as the resistance. Thus, the potential difference, $\Delta \mathrm{V}$ between the potential electrodes $\left(\mathrm{P}_{1}\right.$ and $\left.\mathrm{P}_{2}\right)$ can be measured as follows

$\Delta \mathrm{V}=\frac{\rho \mathrm{I}}{2 \pi}\left(\frac{1}{\mathrm{C}_{1} \mathrm{P}_{1}}-\frac{1}{\mathrm{C}_{2} \mathrm{P}_{1}}-\frac{1}{\mathrm{C}_{1} \mathrm{P}_{2}}+\frac{1}{\mathrm{C}_{2} \mathrm{P}_{2}}\right)$

with $\mathrm{C}_{1} \mathrm{P}_{1}, \mathrm{C}_{2} \mathrm{P}_{1}, \mathrm{C}_{1} \mathrm{P}_{2}$ and $\mathrm{C}_{2} \mathrm{P}_{2}$ being the distance between the electrodes. Then, the electrical resistivity can be determined from the following

$\rho=\left(\frac{1}{\left(\frac{1}{\mathrm{C}_{1} \mathrm{P}_{1}}\right)-\left(\frac{1}{\mathrm{C}_{2} \mathrm{P}_{1}}\right)-\left(\frac{1}{\mathrm{C}_{1} \mathrm{P}_{1}}\right)+\left(\frac{1}{\mathrm{C}_{2} \mathrm{P}_{2}}\right)}\right) \frac{\Delta V}{\mathrm{I}}$

where $\mathrm{K}$ is the geometric factor which depends on the electrodes configuration [13-14,4]. 


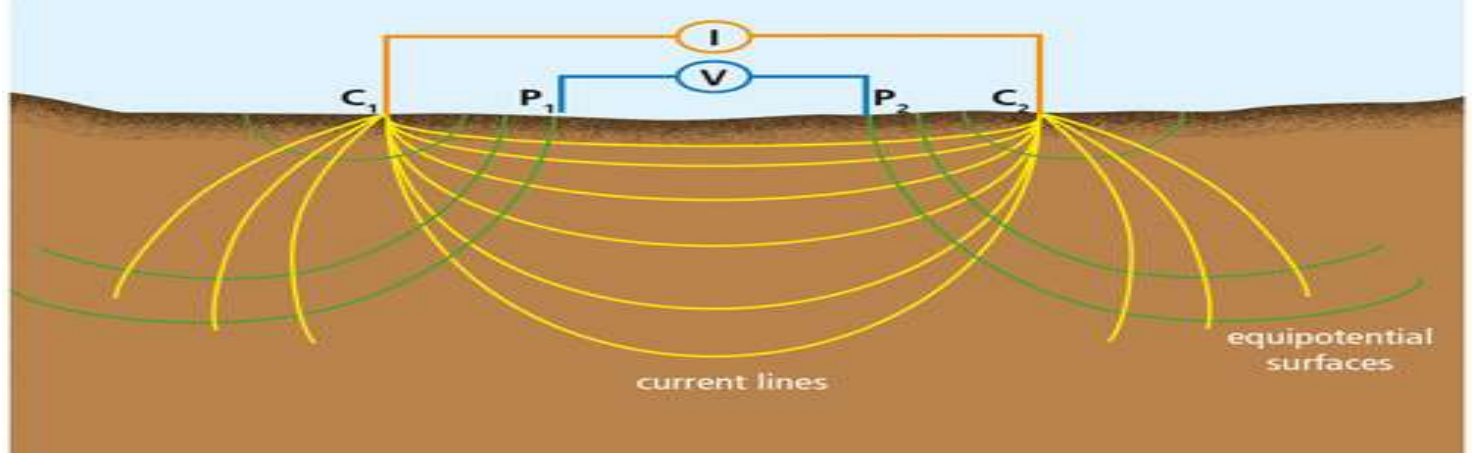

Fig.1.Current distribution in a homogenous soil

\subsection{Application of Resistivity Measurement in Electrical Field}

In electrical field, soil resistivity is one of the important parameters in designing a grounding system. A safe grounding system can be achieved by enabling the fault current to be distributed into the ground without exceeding any operating or equipment limits which can disrupt the continuity of the electrical supply and to ensure the safety of humans in the area of earthed facilities from any risk of electric shock during electrical system faults and lightning [15]. Thus, a proper grounding requires low resistivity soil as it should provide a low-resistance path for current to flow into the ground.

As explained previous, soil resistivity is a function of many soil factors and thus the changing in these factors can significantly affect the impedance of the soils. Numerous researches have been conducted to study the impact of the soil resistivity variation towards the safety of the grounding system. In [16] found that the changes of soil resistivity due to the seasonal variations exceeded the permissible limits of touch and step voltages during the period of experiment. Thus, a safety assessment is crucial in monitoring the soil resistivity variation as it can affect the safety of the earthing system [26].

\section{METHODOLOGY}

This project attempts to conduct and investigate the underground resistivity variation at polar region specifically at the Antarctic continent. Thus, a geo-electrical resistivity method was implemented at King Sejong Station which is located in the Barton Peninsula, King George Island, Antarctic $\left(62^{\circ} 13^{\prime} \mathrm{S}, 58^{\circ} 47^{\prime} \mathrm{W}\right)$ [17]. The experiment was carried out during summer as 
the island was almost ice-free which enable us to conduct the in situ resistivity measurement in exploring the characteristic of underground resistivity variation at high latitude region. The map and aerial view of the site location are presented in Fig. 2 and Fig. 3 respectively [18-19].

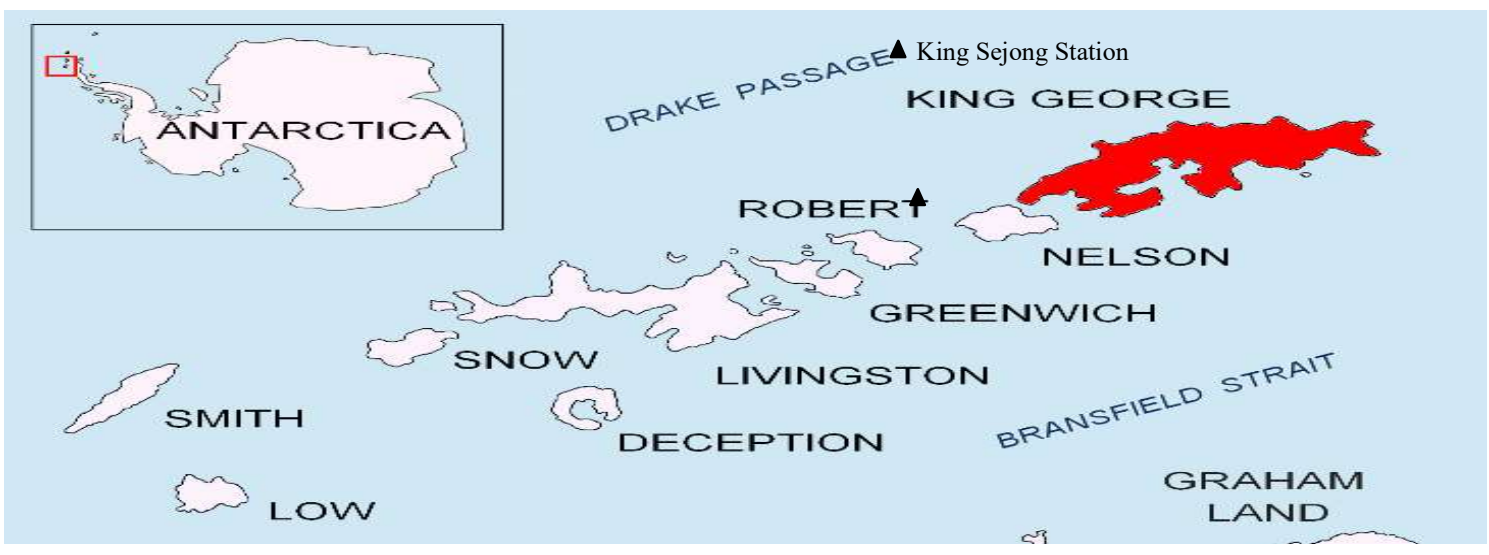

Fig.2. Map of King George Island where King Sejong Station is located (modified)

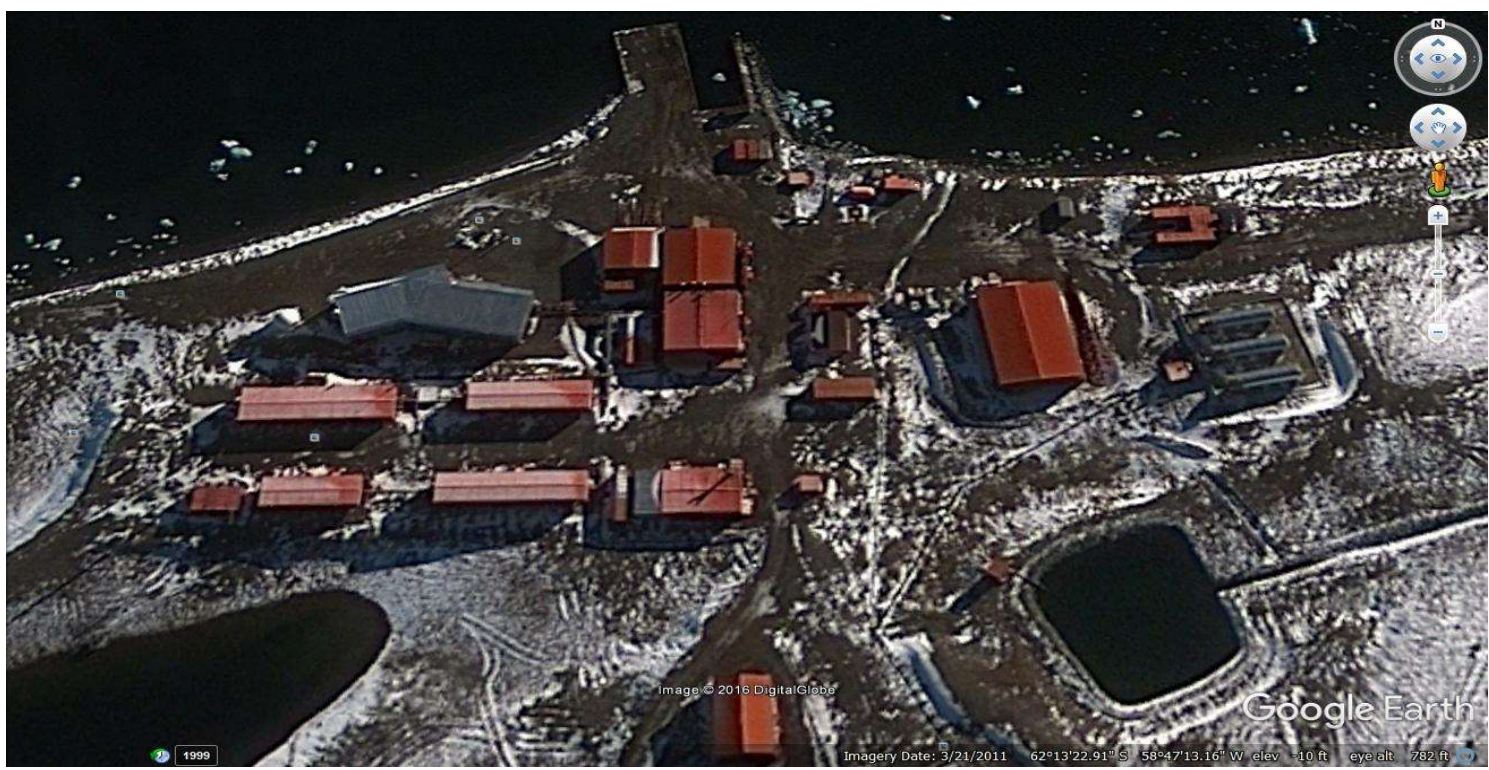

Fig.3. Satellite view of King Sejong Station, Antarctic

The most commonly used electrode configurations in underground resistivity measurement are Wenner and Schlumberger arrays in which both methods deploy four-point electrodes in determining the underground resistivity. For this project, we adopted Wenner array as it has a simpler geometry with equal distance between each electrode compared to the Schlumberger [13]. The spacing, $\mathrm{d}$ was maintained at $3 \mathrm{~m}$ during the period of experiment and the resistivity data were taken for each 3-hour interval. Fig. 4 presents the electrodes arrangement for Wenner configuration. 


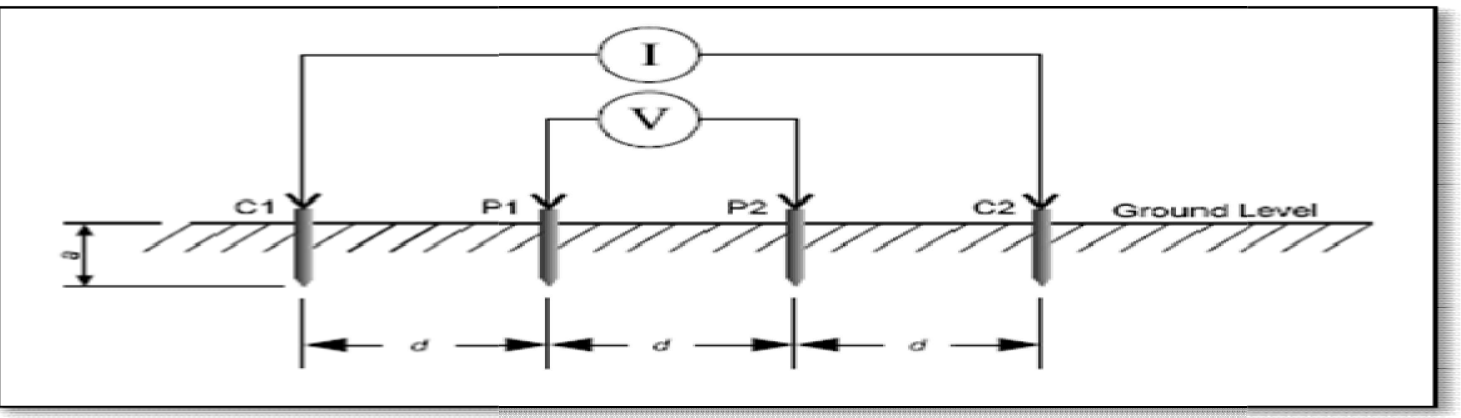

Fig.4. A schematic diagram of Wenner array

From the measurement, the value of apparent resistivity $\left(\rho_{\mathrm{a}}\right)$ is obtained by using this formula

$\rho \mathrm{a}=\mathrm{k} \frac{\Delta \mathrm{V}}{\mathrm{I}}$

Thus,

$\rho \mathrm{a}=2 \pi \mathrm{dR}$

(8)

with $\mathrm{k}=2 \pi \mathrm{d}$ is the geometric factor for Wenner array where $\mathrm{d}$ is the electrode spacing [13].

Fig. 5 shows the experiment setup of the underground resistivity measurement at King Sejong Station

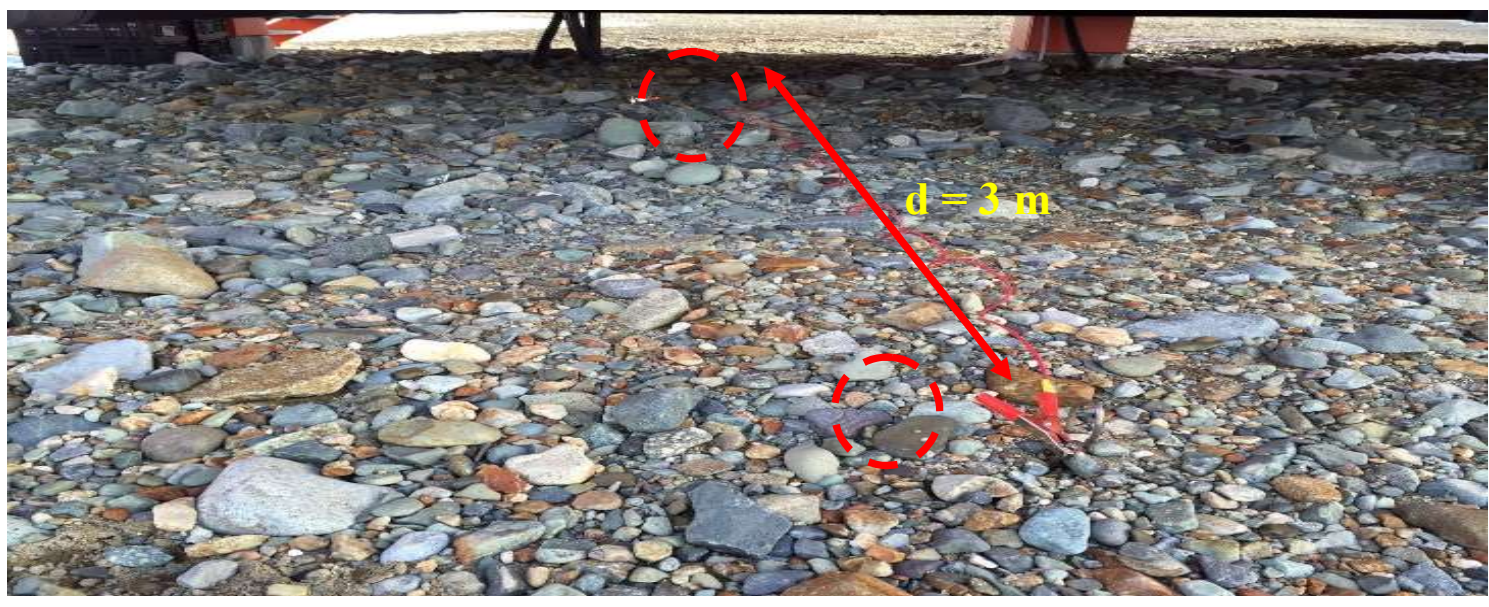

Fig.5.Electrodes are placed into the ground which are connected to the resistivity meter using cables

\section{RESULTS AND DISCUSSION}

The discussion of the results begin with the analysis of space weather activities during the period of measurement since polar region is highly exposed to the geomagnetic disturbance, 
as it has direct geophysical effects during electromagnetic coupling between the Sun and the Earth. The space weather data were retrieved from the ACE Data Browser measured by the Advance Composition Explorer (ACE) satellite.

Fig. 6 shows the graph of solar wind speed, solar wind dynamic pressure and solar wind input energy data. Based on the graph, the speed varies between $300 \mathrm{~km} / \mathrm{s}$ to $400 \mathrm{~km} / \mathrm{s}$ with average speed is $350 \mathrm{~km} / \mathrm{s}$. The speed of solar wind can be categorized as slow solar wind and no significant fluctuations were observed during this period. Meanwhile, the solar wind dynamic pressure shows a high variation on the first several hours and maintain a steady variation afterward. On the other hand, solar wind input energy shows an irregular pattern along the period. An increase in input energy was spotted on the second day starting at 0500 UT which probably due to the co-rotating interacting region (CIR) caused by the accumulation of slow solar wind.
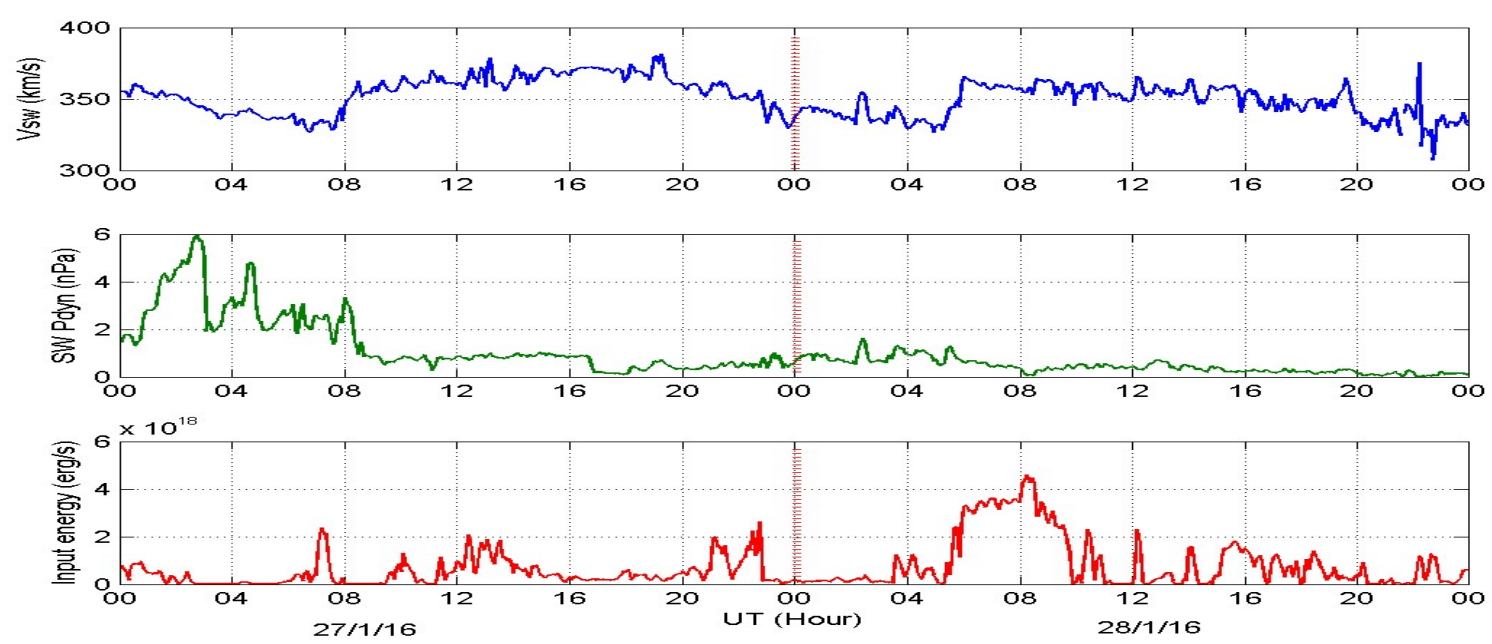

Fig.6.Variations of solar wind speed, Vsw, solar wind dynamic pressure, Pdyn and solar wind input energy, IE

Apart from that, data of Polar Cap (PC) index at South Pole region shows consistency with the sudden increase of Vsw with slight time delay as it is an empirical magnetic activity index retrieved from the ground-based station. As PC index is the ground analogue of interplanetary parameters, it can be used to analyse the geo-effectiveness of Interplanetary Magnetic Field (IMF). Fig. 7 shows the subplot of IMF Bz and PC index which a large increase of PC index can be observed starting from 0800 UT on the second day, which indicates the geo-effective of solar wind acting on the magnetosphere. In summary, the space weather [23] activity 
exhibits normal variation during quiet period as no prominent changes were observed during this period.
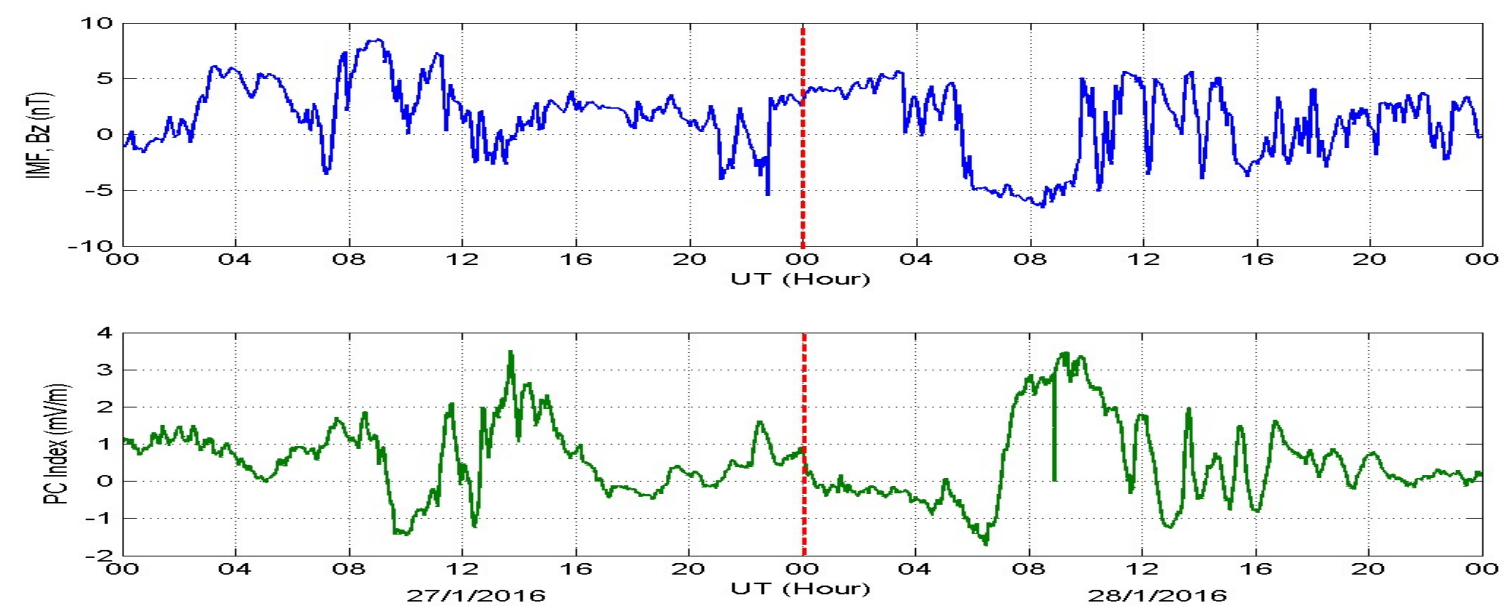

Fig.7.Variations of IMF Bz and PC index of South Pole region

From the resistivity measurement, the underground resistivity data have been collected and tabulated as in Table 3. Fig. 8 presents the graph of underground resistivity variation measured at King Sejong Station, Antarctic. From the graph, a distinct underground resistivity variation can be observed over the time. 
Table 3. Variation of underground resistivity at King Sejong Station, Antarctic

\section{Universal Time (UT) Underground Resistivity ( $\Omega \mathrm{m})$}

\begin{tabular}{ccc}
\hline 27/1/2016 & 11 & 620 \\
\cline { 2 - 3 } & 14 & 621 \\
\cline { 2 - 3 } & 17 & 628 \\
\hline \multirow{28}{28/1/2016}{} & 20 & 631 \\
\cline { 2 - 3 } & 02 & 628 \\
\cline { 2 - 3 } & 05 & 616 \\
\cline { 2 - 3 } & 08 & 623 \\
\hline 14 & 624 \\
\hline & 11 & 624 \\
\hline 20 & 626 \\
\hline & 23 & 630 \\
\hline
\end{tabular}

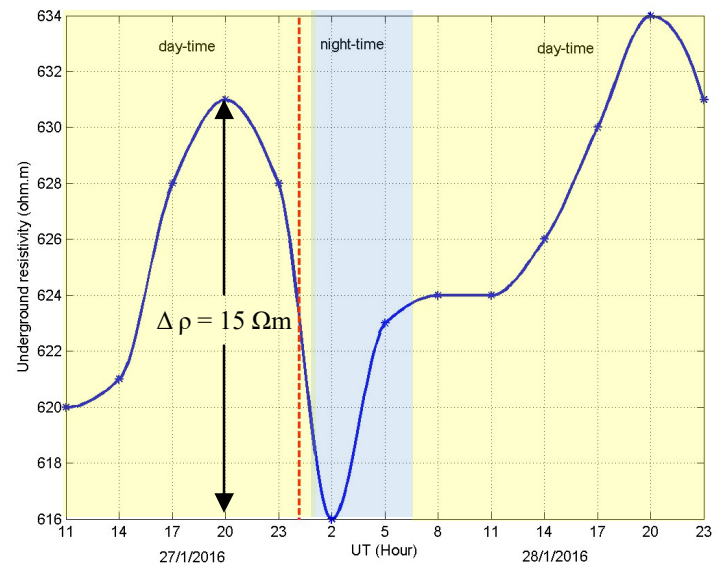

Fig.8. Graph of underground resistivity variation at King Sejong Station, Antarctic From the physical structure of the soils, it can be assumed that the measured area beneath the point surface is composed of rocky soils which justify its high resistivity values. Based on Fig. 8 , the reading of underground resistivity started to increase during day-time until it reached its maximum before started to decline as it approaching night-time. The highest underground 
resistivity reading is recorded during day-time which is $631 \Omega \mathrm{m}$ on the $27^{\text {th }}$ January 2016 and $634 \Omega \mathrm{m}$ on the $28^{\text {th }}$ January 2016. Meanwhile, the underground resistivity dropped to its minimum during night-time with a reading of $616 \Omega \mathrm{m}$.

Since the experiment was conducted during summer which was a winter solstice for the North Pole, it can be seen that the period of day-time is longer than the night-time. This is due to the fact that the distance of the Earth is the closest to the Sun during summer which is also known as Perihelion as illustrated in Fig. 9 [20]. The Earth is tilted at an angle of $23.5^{\circ}$ to the normal of the orbit plane and causes the southern hemisphere to receive more solar radiation compared to the northern hemisphere. This is why the north pole region experiences winter while the south pole region is in summer during winter solstice and thus explains the longer period of daylight at the southern hemisphere during summer.
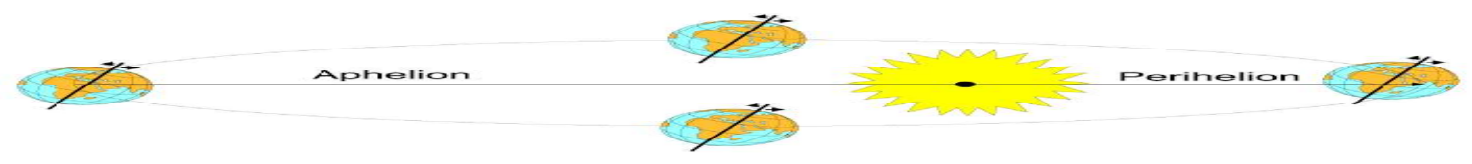

Fig.9.The elliptical orbit of the Earth with regard of the Sun. The Aphelion and Perihelion are described as the longest and shortest distance from the center point of the Earth to the Sun's center point respectively

From the analysis, a plausible reason can be assumed to explain the changes in the underground resistivity variation based on the changing in soil moisture content. During day-time, the Earth receives maximum solar radiation and reaches the ground where it gives warmth to the Earth's surface. The increasing in the ambient temperature causes the ground to dry and hence lower the soil moisture content. Basically, lower soil moisture content will results to the increase in electrical resistivity. In principal, the presence of water in the pores drives the transportation of electrical current as water is a good electrical conductor. Therefore, low moisture content will decrease the electrical conductivity and thus increases the electrical resistivity [21]. Hence, this could possibly explains the variation of underground resistivity variation during day-time and night-time.

In addition, we also analysed the underground resistivity variation at equatorial region where the resistivity measurement was conducted at Langkawi National Observatory (LNO), Malaysia. As shown in Fig. 10, it can be seen that the variation varies according to time, ranging from $136 \Omega \mathrm{m}$ to $139 \Omega \mathrm{m}$. In general, the underground resistivity data shows highest 
reading during day-time while the minimum reading can be observed during night-time.

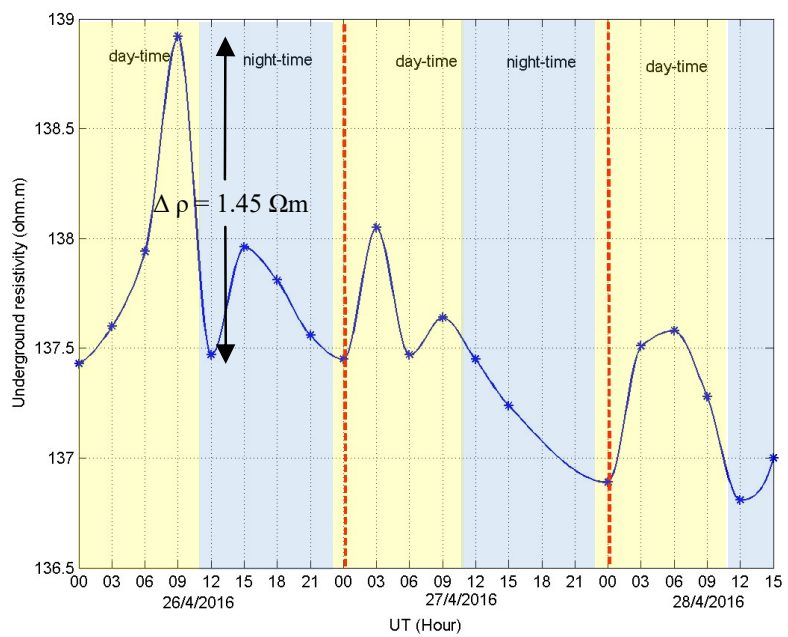

Fig.10.Variation of underground resistivity at LNO (equatorial region)

For comparison, we have calculated the peak-to-peak difference of underground resistivity, $\Delta \rho$ between the day-time and night-time for both locations. The $\Delta \rho$ at King Sejong Station is 15 $\Omega \mathrm{m}$ which is higher than the $\Delta \rho$ at LNO which is $1.45 \Omega \mathrm{m}$. This could be due to the different types of soil at both locations in which the soils at King Sejong Station are more rocky and loosely-arranged while the soils at LNO are rather sandy and compact. As mentioned earlier, soil resistivity is an intrinsic property and hence, different types of soil have different ability to oppose the flow of electrical current. Thus, this influences on how it corresponds to the changes in other soil conditions such as moisture content, temperature and porosity.

\section{CONCLUSION}

The geo-electrical resistivity measurement has been successfully conducted at King Sejong Station, Antarctic. The four-point electrode method with Wenner configuration was selected in this study. In summary, the 3-hour interval of underground resistivity variation at King Sejong Station has been analysed and showed a local-time dependence as it varies with the changes of day-time and night-time. This is due to the influence of solar radiation [24], which could be relate with the temperature [25] changes at the ground surface and result in the changing of the soil moisture content.

As for further improvement, we recommend a longer period of resistivity measurement need 
to be conduct in order to establish a concrete analysis and understanding on the underground [22] resistivity variation at high latitude region.

\section{ACKNOWLEDGEMENTS}

We acknowledge King Sejong Station, Antarctic and Langkawi National Observatory (LNO), Malaysia for providing us place to conduct underground resistivity measurement. The authors also would like to express our gratitude to ACE Science Center website, National Aeronautics and Space Administration (NASA) for supplying 5-minute average of space weather data. PC index data were retrieved from the Department of Geophysics, Arctic and Antarctic Research Institute. This project is financially supported by Sultan Mizan Antarctic Research Foundation, YPASM (Code No. YPASM/Grant/12-2014/JLD.1 (23)), Research Acculturation Grant Scheme, RAGS (600-RMI/RAGS 5/3 (155/2014))and Faculty of Electrical Engineering, UiTM Shah Alam for their continuous support and valuable suggestions in order to complete this project.

\section{REFERENCES}

[1] SubSurface Surveys and Associates Inc. Geophysical methods and applications. 2007,http://www.subsurfacesurveys.com/pdf/Methods.pdf

[2] Institute of Electrical and Electronics Engineers (IEEE). IEEE Std 81-2012: IEEE guide for measuring earth resistivity, ground impedance and earth surface potential of a grounding system. 2012, http://ieeexplore.ieee.org/stamp/stamp.jsp?arnumber=6392181

[3] British Standards Institution (BSI).BS 7430:2011: Code of practice for protective earthing

of electrical installations. 2011, http://www.iso-iran.ir/standards/bs/BS_7430_2011_,_Code_of_Practice.pdf

[4] Samouëlian A, Cousin I, Tabbagh A, Bruand A, Richard G. Electrical resistivity survey in soil science: a review. Soil and Tillage Research, 2005, 83(2):173-193

[5]Chik Z, Islam S T. Finding soil particle size through electrical resistivity in soil site investigations. Electronic Journal of Geotechnical Engineering, 2012, 17:1867-1876

[6] Lightning and Surge Technologies.Earthing techniques. 2012,http://www.lightningman.com.au/Earthing.pdf 
[7] Buresova D, LastovickaJ, Hejda P, Bochnicek J. Ionospheric disturbances under low solar activity conditions. Advances in Space Research, 2014, 54(2):185-196

[8] Biktash L Z, Maruyama T, Nozaki K. The solar wind control of the equatorial ionosphere dynamics during geomagnetic storms. Advances in Space Research, 2008, 41(4):562-568

[9] Egbert G D. On the generation of ULF magnetic variations by conductivity fluctuations in a fault zone. Pure and Applied Geophysics, 2002, 159(6):1205-1227

[10]Australian Antarctic Division (AAD). Antarctic weather. 2002,http://www.antarctica.gov.au/about-antarctica/environment/weather

$\begin{array}{llll}\text { [11]Landcare } & \text { Research. } & \text { Antarctic } & \text { soils. }\end{array}$ http://www.landcareresearch.co.nz/science/soils-and-landscapes/antarctic-soils [12]Applied Scientific Services and Technology Pty.Ltd.Overview of geophysical techniques. 2010, http://asstgroup.com/techniques.html

[13] Herman R. An introduction to electrical resistivity in geophysics. American Journal of Physics, 2001, 69(9):943-952

[14]Loke M H, Chambers J E, Rucker D F, Kuras O, Wilkinson P B. Recent developments in the direct-current geoelectrical imaging method. Journal of Applied Geophysics, 2013, 95:135-156

[15] Kumar A, Seedhar H R. Grounding system for high resistivity limited area substations in hilly region of Himachal Pradesh. In 16th National Power Systems Conference, 2010, pp. 516-522

[16] Abdullah N, Marican A M A, Osman M, Rahman N A A. Case study on impact of seasonal variations of soil resistivities on substation grounding systems safety in tropical country. In 7th IEEE Asia-Pacific International Conference on Lightning, 2011, pp. 150-154

[17]Latitude.to. $\quad$ King Sejong 2017, http://latitude.to/articles-by-country/aq/antarctica/65925/king-sejong-station [18]Wikimedia Commons. King George Island. 2014, https://commons.wikimedia.org/wiki/File:King-George-Island-location-map.png [19]King Sejong Station. Google Earth.

[20]Peter J N. Chapter 3: Earth-sun relations. 2017, http://www.farmingdale.edu/faculty/peter-nolan/pdf/Ch03PhysAtm.pdf 
[21]Hayat M N. The effects of moisture, cation concentration, temperature, density and composition of soils on their electrical resistivity. Master thesis, Ontario: Brock University, 1984

[22] Farah A M K, Khairunnisa N J, Norbi A A R, Muhammad S J, Mohamad H J, Zairi I R.Implementation of earth conductivity experiment to evaluate underground parameters. ARPN Journal of Engineering and Applied Sciences, 2017, 12(10):3271-3277

[23] Nur A Z, Mohamad H J, SitiZA Z, Zairi I R. Development of space weather monitoring platform for space and earth's electromagnetism observation. ARPN Journal of Engineering and Applied Sciences, 2017, 12(10):3308-3311

[24] Afifah T, Nor A Z, Atiqah A R, Mohamad H J, Zairi I R.Variation of VHF/UHF of forward scattering radar due to solar radiation. ARPN Journal of Engineering and Applied Sciences, 2017, 12(10):3278-3284

[25] Rina A, Zairi I R, Nik N S N D, Syila I I, Rosmawati S, Mohamad H J. Design an automatic temperature control system for smart tudungsaji using Arduino microcontroller. ARPN Journal of Engineering and Applied Sciences, 2016, 11(16):9578-9581

[26] Fadhli D M F, Tatang M, Zairi I R, Mohamad T M, Wan A K W C, Mohamad H J. Supervisory fertigation system using interactive graphical supervisory control and data acquisition system. International Journal on Advanced Science, Engineering and Information Technology, 2016, 6(4):489-494

\section{How to cite this article:}

Juhari K. N., Mohd. Kasran F. A., Jusoh M. H.Investigation of underground resistivity measurement at King Sejong Station, Antarctic. J. Fundam. Appl. Sci., 2017, 9(5S), 498-513. 